\title{
A AGENDA 2030 E AS EXPECTATIVAS DA SOCIEDADE QUANTO À ATUAÇÃO DO PODER JUDICIÁRIO NO ENFRENTAMENTO DA CORRUPÇÃO
}

\author{
Roberto Carvalho Veloso ${ }^{1}$ \\ Marco Adriano Ramos Fonsêca ${ }^{2}$
}

\section{Resumo:}

Análise reflexiva do enfrentamento da corrupção à luz da Agenda 2030 da ONU e das expectativas da sociedade brasileira quanto à atuação do Poder Judiciário, a partir das percepções obtidas em pesquisas científicas de opinião pública conduzidas por instituições nacionais e internacionais. Para atender à proposta do estudo, foram utilizados os métodos indutivo, histórico-jurídico e jurídico-descritivo, valendo-se da técnica de pesquisa de documentação indireta, abrangendo a pesquisa bibliográfica e a pesquisa documental. Os resultados confirmaram a hipótese do estudo, e ao final são indicadas as percepções da sociedade quanto à atuação do Poder Judiciário no julgamento dos crimes de corrupção.

Palavras-Chave: Corrupção no Brasil. Enfrentamento à Corrupção. Agenda 2030 da ONU. Expectativas da sociedade. Atuação do Judiciário.

\section{THE 2030 AGENDA AND THE EXPECTATIONS OF SOCIETY REGARDING THE PERFORMANCE OF THE JUDICIARY IN TACKLING CORRUPTION}

\begin{abstract}
:
Reflexive analysis of the fight against corruption in the light of the UN 2030 Agenda and the expectations of Brazilian society regarding the performance of the Judiciary, from the perceptions obtained in scientific research of public opinion conducted by national and international institutions. To meet the proposal of the study, the inductive, historical-legal and legal-descriptive methods were used, and the indirect documentation search technique, including bibliographic and documentary research. The results confirmed the study's hypothesis, and in the end, society's perceptions of the Judiciary's role in judging corruption crimes are indicated.
\end{abstract}

Keywords: Corruption in Brazil. Tackling Corruption. UN 2030 Agenda. Society's expectations. Performance of the Judiciary.

\section{INTRODUÇÃO}

\footnotetext{
1 Juiz Federal da Seção Judiciária do Maranhão. Doutor e Mestre em Direito pela Universidade Federal de Pernambuco. Coordenador do Programa de Pós-Graduação em Direito e Instituições do Sistema de Justiça da Universidade Federal do Maranhão. Professor Associado da Universidade Federal do Maranhão dos cursos de graduação e do Programa de Mestrado em Direito e Instituições do Sistema de Justiça. Professor Colaborador da Universidade Autónoma de Lisboa - Portugal. Membro do Conselho Superior da Escola Nacional de Formação e Aperfeiçoamento de Magistrados - ENFAM. velosorc@uol.com.br.

2 Juiz de Direito da $1^{\text {a }}$ Vara de Pedreiras/MA. Mestrando em Direito e Instituições do Sistema de Justiça da Universidade Federal do Maranhão. Especialista em Direito Processual pela Universidade da Amazônia UNAMA. Professor do Curso de Direito da Faculdade de Educação São Francisco - FAESF. $1^{\circ}$ Vice-Presidente da Associação dos Magistrados do Maranhão - AMMA. marfonseca@tjma.jus.br.
} 
A corrupção constitui-se em fenômeno generalizado, sistêmico e disseminado em todos os níveis das organizações públicas, com forte impacto social e econômico, repercutindo nos indicadores de desenvolvimento humano, e nesse cenário o seu enfrentamento é uma importante medida de prevenção e repressão a violações de Direitos Humanos.

Corroborando essa perspectiva, a Carta das Nações Unidas consagrou o compromisso da comunidade internacional em viabilizar uma cooperação integrada para a resolução dos problemas internacionais de caráter econômico, social, cultural ou humanitário, bem como, para a promoção e estímulo do respeito aos direitos humanos e às liberdades fundamentais para todos.

Nesse sentido, a Organização das Nações Unidas (ONU) contemplou o enfrentamento à corrupção no Pacto Global de 2000 e na Agenda 2030 aprovada em 2015, sinalizando uma orientação à comunidade internacional para um maior esforço para a implementação de políticas efetivas contra a corrupção, mediante a participação da sociedade e refletindo princípios do Estado de Direito, tais como, a integridade, a transparência e a accountability, entre outros.

Diante desse panorama, o presente artigo tem por objetivos apresentar uma análise reflexiva da atuação da ONU na sistematização da cooperação internacional para o enfrentamento à corrupção, especialmente à luz da Agenda 2030, e quais são as expectativas da sociedade brasileira quanto à atuação do Poder Judiciário nesta temática, a partir das percepções obtidas em pesquisas científicas de opinião pública conduzidas por instituições nacionais e internacionais.

Nesse moldes, para alcançar as intencionalidades da abordagem desta produção científica será utilizado o raciocínio indutivo e dos métodos de investigação histórico-jurídico e jurídico-descritivo ${ }^{3}$, já que pretendemos desenvolver uma pesquisa de natureza descritiva, mediante a coleta, observação e análise de dados particulares para a obtenção de conclusões gerais, para identificar os Objetivos de Desenvolvimento Sustentável (ODS) que integram a Agenda 2030 da ONU no enfrentamento à corrupção e apresentar as expectativas da sociedade quanto ao paradigma da atuação institucional do Poder Judiciário, a partir de pesquisas realizadas por instituições de âmbito nacional e internacional, valendo-nos da

\footnotetext{
${ }^{3}$ Nesta produção acadêmica serão adotadas as definições metodológicas das autoras Gustin e Dias (2015, p. 2227).
} 
técnica de pesquisa de documentação indireta, abrangendo a pesquisa bibliográfica e a pesquisa documental.

A pesquisa bibliográfica será realizada a partir de obras de referência e artigos científicos especializados, bem como, por meio de relatórios e de pesquisas produzidas por instituições científicas de âmbito nacional e internacional sobre o assunto, procedendo-se a análise e interpretação dos dados estatísticos apurados, mediante a descrição e a avaliação das generalizações obtidas a partir dessas informações coletadas.

Já a pesquisa documental consistirá no levantamento de dispositivos constitucionais, tratados internacionais, leis, resoluções, portarias e outros atos normativos relacionados à temática.

Nessa linha, o presente estudo justifica-se pela necessidade de incremento de pesquisas que se proponham a investigar o combate à corrupção no âmbito da atuação das Instituições do Sistema de Justiça, bem como, para fomentar a prática de observação acadêmica da realidade nacional.

A partir do exercício crítico dos vários registros e antecedentes históricos relevantes, ao longo da presente produção foram desenvolvidas estruturações argumentativas específicas para a observação e valoração da sistematização de estratégias institucionais para o enfrentamento à corrupção, de forma a evidenciar a conjugação de esforços no campo internacional e sua influência quanto ao paradigma de atuação das instituições do Sistema de Justiça no Brasil, que devem convergir para a prevenção e repressão a tais espécies de desvios, e ao final da pesquisa são indicadas as contribuições da ONU no impulsionamento da cooperação internacional para o enfrentamento à corrupção e apresentadas as percepções da sociedade quanto à atuação do Poder Judiciário nesta temática.

\section{A AGENDA 2030 E A ATUAÇÃO DA ONU NO ESTÍMULO AO ENFRENTAMENTO À CORRUPÇÃO}

O enfrentamento da corrupção é uma importante medida de prevenção a violações de Direitos Humanos, porque os recursos destinados à saúde, educação, previdência, segurança pública e outras políticas públicas, imprescindíveis para a efetividade dos direitos fundamentais, são justamente os mais afetados pelos desvios éticos na administração pública.

Conforme a Transparência Internacional (2018, p. 12) o enfrentamento à corrupção exige uma abordagem que reforce a legitimidade e a independência das Instituições do 
Sistema de Justiça de todos os países, mediante o aprimoramento dos mecanismos de prevenção e o fortalecimento dos instrumentos necessários à responsabilização de corruptos e corruptores.

Nessa linha, é importante ressaltar a preocupação da comunidade internacional acerca da temática, reconhecendo a necessidade de cooperação internacional e da implementação de um enfoque amplo e multidisciplinar para prevenir e combater eficazmente a corrupção.

Nesse sentido, elucidativas são as lições de Silva (2019, p. 39-40) afirmando que “verifica-se um movimento de internacionalização no combate à corrupção por instrumentos como Convenções e Tratados, uma vez que a sua prática ultrapassa os limites do Estado, para se configurar um fenômeno econômico mundial.".

Nesse sentido, o compromisso internacional com a promoção e proteção de direitos humanos no Estado de Direito foi reafirmado mediante a proclamação da Declaração Universal dos Direitos Humanos de 1948, pela qual os Estados-membros da ONU decidiram promover o progresso social e melhores padrões de vida e a alcançar, em cooperação com as Nações Unidas, a promoção do respeito universal e da observância dos direitos humanos e das liberdades fundamentais, e consequentemente, o combate à corrupção deve ser concebido entre as ações a serem promovidas e estimuladas de maneira uniforme em âmbito internacional.

Ressalte-se, ainda, a iniciativa da Organização para a Cooperação e Desenvolvimento Econômico (OCDE), fundada em 1961 e com sede em Paris, França, que consiste numa organização econômica intergovernamental que não integra a estrutura das Nações Unidas, que editou a Convenção sobre o Combate da Corrupção de Funcionários Públicos Estrangeiros em Transações Comerciais Internacionais, de 17 de dezembro de 1997, que no Brasil foi ratificada pelo Congresso Nacional por meio do Decreto Legislativo $\mathrm{n}^{\mathrm{o}} 125$, de 14 de junho de 2000, e foi promulgado pelo Decreto $n^{\circ}$. 3.678, de 30 de novembro de 2000 (BRASIL, 2000).

Conforme o referido ato multilateral, reconheceu-se que a corrupção é um fenômeno difundido nas transações comerciais internacionais, que desperta sérias preocupações morais e políticas, abala a boa governança e o desenvolvimento econômico, e distorce as condições internacionais de competitividade, ressaltando que a obtenção de avanços no enfrentamento da corrupção exige esforços tanto em âmbito nacional quanto internacional, na cooperação, monitoramento e acompanhamento multilaterais, incluindo ações das Nações Unidas, da 
comunidade internacional, companhias, organizações empresariais e organizações nãogovernamentais.

Ao abordar a Convenção da OCDE, Florêncio Filho e Silva (2019, p. 238-239) apresentam as balizas de uma perspectiva colaborativa da política criminal internacional, pautada na cooperação entre setor privado e as instituições públicas fiscalizadoras e encarregadas da persecução penal, consistindo na chamada autorregulação regulada.

Destaque-se, ainda, a aprovação da Convenção Interamericana contra a Corrupção, no âmbito dos países-membros da Organização dos Estados Americanos (OEA), firmada em 29 de março de 1996, em Caracas, Venezuela. No Brasil, ela foi aprovada pelo Decreto Legislativo $\mathrm{n}^{\mathrm{o}} 152$, de 25 de junho de 2002, e promulgada pelo Decreto Presidencial $\mathrm{n}^{\mathrm{o}} 4.410$, de 7 de outubro de 2002 (BRASIL, 2002).

Conforme as lições de Godinho (2020, p. 374) “[...] representa o primeiro instrumento internacional a tratar do tema da corrupção transnacional e constitui o exemplo pioneiro de ação jurídica regional no mundo em desenvolvimento".

Seguindo essa trilha foi editada a Convenção das Nações Unidas contra a Corrupção, conhecida como Convenção de Mérida, adotada pela Assembleia Geral das Nações Unidas em 31 de outubro de 2003, da qual o Brasil é signatário e foi ratificada pelo Decreto Legislativo no 348/2005, e promulgada pelo Decreto Presidencial no 5.687/2006.

Nos moldes do preâmbulo da referida convenção (ORGANIZAÇÃO DAS NAÇÕES UNIDAS, 2021b), afirma-se que a corrupção "deixou de ser um problema local para converter-se em um fenômeno transnacional que afeta todas as sociedades e economias", sendo necessária a cooperação internacional para prevenir e lutar contra a corrupção.

$\mathrm{Na}$ referida Convenção Internacional os Estados subscritores reconheceram a gravidade das consequências da corrupção para a estabilidade e a segurança das sociedades, ao enfraquecer as instituições e os valores da democracia, da ética e da justiça e ao comprometer o desenvolvimento sustentável e o Estado de Direito, e suas conexões com outras formas de criminalidade, especialmente o crime organizado e a lavagem de dinheiro, comprometendo uma proporção importante dos recursos dos Estados e ameaçando a estabilidade política e o desenvolvimento sustentável dos mesmos, comprometendo-se a promover e fortalecer as medidas para prevenir e combater mais eficaz e eficientemente a corrupção, facilitar e apoiar a cooperação internacional e a assistência técnica na prevenção e na luta contra a corrupção, incluída a recuperação de ativos.

Merece destaque, ainda, a Convenção das Nações Unidas Contra o Crime 
Organizado Transnacional, denominada de Convenção de Palermo, ratificada pelo Decreto n. 5.015/2004 (BRASIL, 2004), que visa promover a cooperação para prevenir e combater mais eficazmente a criminalidade organizada transnacional, estabelecendo compromissos e deveres dos Estados subscritores para a adoção de medidas eficazes de ordem legislativa e administrativa para promover a integridade e prevenir, detectar e punir a corrupção dos agentes públicos, inclusive, conferindo às autoridades dos Estados Partes independência suficiente para impedir qualquer influência indevida sobre a sua atuação.

Segundo as lições de Pinheiro e Pinheiro (2020, p. 15):

\begin{abstract}
percebe-se que a tutela mínima anticorrupção é imperativo decorrente da conjugação entre a Constituição Federal e os Tratados/Convenções Internacionais Anticorrupção que o Brasil subscreveu e incorporou ao ordenamento jurídico nacional, sendo pressuposto indispensável para a verdadeira existência de um Estado comprometido com a prevenção e repressão à corrupção.
\end{abstract}

Nesse sentido, importante registrar que em 2000 a ONU lançou o Pacto Global das Nações Unidas ${ }^{4}$, que visa estimular uma cultura anticorrupção e de compliance na iniciativa privada, alinhando as operações e estratégias empresariais com os dez princípios universalmente aceitos nas áreas de direitos humanos, trabalho, meio ambiente e combate à corrupção, consistindo no compromisso das empresas em trabalhar contra a corrupção em todas as suas formas, incluindo extorsão e suborno.

Reforçando esta atuação estratégica das Nações Unidas no combate à corrupção, merece destaque a aprovação da Agenda 2030 da $\mathrm{ONU}^{5}$, que foi subscrita por 193 Países, inclusive o Brasil, e incorporou os 8 Objetivos de Desenvolvimento do Milênio (Agenda 2015 - período 2000/2015), ampliando-os para 17 Objetivos de Desenvolvimento Sustentável (ODS), distribuídos em 169 metas, consistindo num plano de ação internacional consubstanciado num pacto pelo cumprimento de compromissos e metas no período de 2016 a 2030, com base no espírito de solidariedade global, com ênfase especial nas necessidades dos mais pobres e mais vulneráveis e com a participação de todos os países, todas os grupos interessados e todas as pessoas.

O tema do enfrentamento à corrupção é descrito no ODS 16 (Paz, Justiça e Instituições Eficazes) que preconiza o compromisso de promover sociedades pacíficas e

\footnotetext{
${ }^{4}$ O Pacto Global foi concebido pelo então secretário-geral das Nações Unidas, Kofi Annan, consistindo numa exortação às empresas mundiais a alinharem suas estratégias e operações a 10 princípios universais nas áreas de Direitos Humanos, Trabalho, Meio Ambiente e Anticorrupção e desenvolverem ações que contribuam para o enfrentamento dos desafios da sociedade. Para maiores detalhes, cf. Organização das Nações Unidas (2021d).

${ }^{5}$ A Agenda 2030 da ONU foi aprovada na Assembleia Geral das Nações Unidas, em Nova York, nos dias 25 a 27 de setembro de 2015, por ocasião das comemorações ao septuagésimo aniversário da instituição. Maiores detalhes, cf. Organização das Nações Unidas (2021a).
} 
inclusivas para o desenvolvimento sustentável, e a construção de instituições eficazes, responsáveis e inclusivas em todos os níveis, sendo especialmente detalhado nas seguintes metas: 16.3 - promover o Estado de Direito, em nível nacional e internacional; 16.4 - reduzir significativamente os fluxos financeiros e de armas ilegais, reforçar a recuperação e devolução de recursos roubados, e combater todas as formas de crime organizado; 16.5 reduzir substancialmente a corrupção e o suborno em todas as suas formas; 16.6 - desenvolver instituições eficazes, responsáveis e transparentes em todos os níveis.

No Brasil, a coordenação da implementação da Agenda 2030 compete à Comissão Nacional para os ODS, criada pelo Decreto $n^{\circ}$ 8.892, de 27 de outubro de 2016 (BRASIL, 2016), para a articulação, a mobilização e o diálogo com os entes federativos e a sociedade civil, elaboração de estudos e proposição de estratégias, instrumentos, ações e programas para a implementação dos ODS, bem como, para identificação, sistematização e divulgação de boas práticas, sendo composta por representantes dos 3 níveis federativos do governo, da sociedade civil e do setor privado.

Nessa linha, a ONU vem promovendo eventos e conferências anticorrupção, especialmente através do Escritório das Nações Unidas sobre Drogas e Crime (UNODC), entre eles tendo destaque a Conferência dos Estados-Partes da Convenção das Nações Unidas contra a Corrupção, em dezembro de 2019, na cidade de Abu Dhabi ${ }^{6}$.

Ressalte-se, por oportuno, que o Conselho Nacional de Justiça (CNJ) por ocasião do XII Encontro Nacional do Poder Judiciário, realizado em Foz do Iguaçu, no dia 3 de dezembro de 2018, deliberou pela inclusão no planejamento do Poder Judiciário para 2020, as metas dos ODS, constituindo a Agenda 2030 no Poder Judiciário ${ }^{7}$, tendo sido instituído o Comitê Interinstitucional destinado a avaliar a integração das metas do Poder Judiciário às metas e indicadores dos ODS, pela Portaria CNJ n 133/2018.

Entre os eventos promovidos pela ONU, em parceria com o CNJ, podemos citar o $1^{\circ}$ Encontro Ibero-Americano da Agenda 2030 no Poder Judiciário, realizado em agosto de 2019, em Curitiba, no qual foi subscrito o Pacto pela Implementação dos Objetivos de Desenvolvimento Sustentável da Agenda 2030 no Poder Judiciário e Ministério Público (CNJ, 2019a) pelo Coordenador do Sistema ONU no Brasil, Niky Fabiancic, o então presidente do CNJ e do Supremo Tribunal Federal (STF), Ministro Dias Toffoli, e a então ProcuradoraGeral da República, Raquel Dodge.

\footnotetext{
${ }^{6}$ Para maiores informações, cf. Organização das Nações Unidas (2021c).

${ }^{7}$ Para maiores esclarecimentos, cf. Conselho Nacional de Justiça (2021).
} 
Na oportunidade, foi publicada a Portaria CNJ n 119/2019 (CNJ, 2019b) criando o Laboratório de Inovação, Inteligência e ODS (LIODS) a quem compete mapear os programas e projetos desenvolvidos pelas redes de inovação dentro do Judiciário, ligados à pauta global da Agenda 2030 e incentivar pesquisas, artigos e estudos sobre os ODS no Poder Judiciário.

Nesse contexto, importante ser ressaltado que o Poder Judiciário Brasileiro é pioneiro no mundo na institucionalização da Agenda 2030 e indexação de sua base de dados de processos a cada um dos 17 Objetivos de Desenvolvimento Sustentável, e a integração da Agenda 2030 passou a ser contemplada na Meta Nacional 9 do Poder Judiciário Brasileiro a partir de 2020, sendo incorporada à Estratégia Nacional do Poder Judiciário 2021-2026, conforme Resolução CNJ no 325/2020 (CNJ, 2020).

Evidencia-se, portanto, os esforços da comunidade internacional para a realização de adaptações legislativas e ações concomitantes à aplicação das convenções internacionais no âmbito de cada país, fortalecendo suas capacidades e criando novas instituições, realçando o reconhecimento da independência do Poder Judiciário e seu papel decisivo na luta contra a corrupção, adotando medidas para reforçar a integridade e transparência, viabilizando um cenário mais auspicioso à prevenção e à repressão uniforme no âmbito internacional.

Estas constatações traduzem a compatibilidade entre os anseios sociais e os valores maiores do ordenamento jurídico, fundamentos do Estado Democrático de Direito, trazendo consigo o conteúdo político-constitucional erigido pela sociedade contemporânea, servindo de instrumental valioso para a aplicabilidade e efetividade das normas constitucionais e infraconstitucionais.

Nesse cenário, a legislação penal nacional encontra estrita consonância com os balizamentos propostos nas diretrizes internacionais, obedecendo ao princípio da reserva legal, e nos crimes contra a administração pública, relacionados diretamente à prática da corrupção, conta com um vasto conjunto normativo.

\section{O ENFRENTAMENTO À CORRUPÇÃO E AS EXPECTATIVAS DA SOCIEDADE QUANTO A ATUAÇÃO DO PODER JUDICIÁRIO}

Nos últimos anos, percebe-se que o tema do enfrentamento à corrupção passou a integrar quase que diariamente a pauta dos noticiários nacionais, e progressivamente o interesse da sociedade em torno do assunto, especialmente ao se considerar que os casos de corrupção comprometem uma proporção importante dos recursos públicos e que ameaçam a 
estabilidade política e o desenvolvimento social e econômico do país.

Conforme as lições de Barroso (2018, p. 31-32), os atos de corrupção consistem ações ou omissões que visam proporcionar vantagem indevida em detrimento da administração pública, e no Brasil alcançou níveis espantosos, endêmicos, consistindo num fenômeno generalizado, sistêmico e plural, envolvendo empresas estatais e privadas, agentes públicos e privados, em verdadeiros esquemas sofisticados de arrecadação e distribuição de dinheiros desviados mediante superfaturamento e outros esquemas.

Torres e Bertoncini (2015, p. 180), ao abordar os efeitos da corrupção, lecionam que “a corrupção impede o desenvolvimento de políticas públicas de auxílio aos necessitados, empobrecendo e fragilizando a sociedade e as pessoas menos favorecidas, levando-as à condição de pobreza extrema sem qualquer perspectiva de solução.”.

Diante desse cenário, evidencia-se uma maior preocupação com as consequências da corrupção no Brasil, periodicamente envolto em escândalos que enfraquecem as instituições e os valores da democracia, concebendo-se a corrupção como um atentado ao Estado Democrático de Direito e aos valores fundamentais da República, necessitando de uma atuação integrada das instituições responsáveis pelo controle social formal para a prevenção e repressão a tais espécies de atos, respeitando os princípios fundamentais do devido processo legal, contraditório e ampla defesa, assegurado a todos, sem distinção.

Refletindo esse novel paradigma, percebe-se os anseios e expectativas da sociedade brasileira que a Administração Pública seja pautada em valores éticos, morais, que prestigiem a cultura da probidade e da integridade ${ }^{8}$, criando condições sociais e culturais para que as pessoas se comportem honestamente, e moldando a atuação das instituições, com o aprimoramento dos mecanismos legais que aperfeiçoem a atuação dos órgãos de controle e do Sistema de Justiça.

Várias pesquisas científicas apontam que a principal preocupação dos brasileiros atualmente é a corrupção, estando a frente de outras pautas relevantes como educação, saúde e desemprego, conforme diagnosticado em recente pesquisa da Fundação Getúlio Vargas (2017, p. 11), que entrevistou 1.568 pessoas, dos quais $63 \%$ (sessenta e três por cento) afirmaram que a corrupção é o tema que mais os angustia no Brasil.

$\mathrm{Na}$ mesma linha, em pesquisa de iniciativa da Associação dos Magistrados

\footnotetext{
${ }^{8}$ Segundo Moisés (2013, p. 175) "denúncias de escândalos envolvendo o uso indevido de recursos públicos são um sinal de progresso em países caracterizados por processos endêmicos de corrupção, pois revelam sinais de pressão da sociedade civil no sentido do estabelecimento de padrões republicanos de comportamento político.”.
} 
Brasileiros $(\mathrm{AMB})^{9}$, foi identificada uma avaliação positiva da atuação do Poder Judiciário, principalmente no enfrentamento à corrupção, posto que para 49\%(quarenta e nove por cento) dos entrevistados a maior contribuição do Judiciário para o país consistia no combate à corrupção, maior índice percentual identificado entre os parâmetros pesquisados, ficando em $2^{\circ}$ lugar na percepção predominante a contribuição do Judiciário para a consolidação da democracia no país (47\% dos entrevistados), reverberando, consequentemente, a percepção da opinião pública acerca da atuação do Judiciário, e demonstrando que a agenda da sociedade é o filtro da avaliação e das expectativas em relação às ações deste Poder $^{10}$.

Consoante o Estudo da AMB (2019, p. 13), dentre os três Poderes, o Judiciário figura como a instituição em que os brasileiros mais confiam para 52\% (cinquenta e dois por cento) dos entrevistados, contra 34\% (trinta e quatro por cento) da Presidência da República e 19\% (dezenove por cento) do Congresso.

Demais disso, em outro indicador, no que diz respeito ao cumprimento de sua missão institucional, a pesquisa da $\operatorname{AMB}$ (2019, p. 40) novamente identifica que o Judiciário tem avaliação positiva da sociedade: para $33 \%$ (trinta e três por cento) dos entrevistados, o Judiciário é o Poder que melhor cumpre o seu papel, enquanto apenas 9\% (nove por cento) escolhem o Legislativo e 8\% (oito por cento) indicam o Executivo.

Destarte, tais pesquisas científicas demonstram que o Poder Judiciário tem sido identificado pela sociedade como elemento decisivo no combate à criminalidade do colarinho branco, especialmente da corrupção, evidenciando os anseios e as expectativas projetadas pela coletividade quanto a atuação das instituições democráticas, especialmente do Sistema de Justiça, num processo de fortalecimento da imagem do Poder Judiciário brasileiro perante a sociedade.

Nesses moldes, conforme Sadek (2010, p. 24) as novas perspectivas consagradas pela Constituição de 1988, com um novo perfil das instituições judiciárias e do Ministério Público, resultante da redemocratização do País, contribuem para formar uma imagem mais democrática da justiça, reforçando, indiretamente, o prestígio da instituição como um todo.

Estas constatações traduzem a compatibilidade entre os anseios sociais e os valores

\footnotetext{
${ }^{9}$ O Estudo da Imagem do Judiciário Brasileiro foi uma iniciativa da AMB, encomendado à Fundação Getúlio Vargas (FGV), que desenvolveu a pesquisa em parceria com o Instituto de Pesquisas Sociais, Políticas e Econômicas (IPESPE). Para maiores detalhes, cf. Associação dos Magistrados Brasileiros (2019).

${ }^{10}$ A pesquisa foi realizada no período de agosto de 2018 a dezembro de 2019 , com a utilização articulada de metodologias e técnicas qualitativas e quantitativas, abrangendo diversos segmentos de público: sociedade, advogados e defensores públicos e formadores de opinião. Também foi investigada a imagem do Judiciário brasileiro nas redes sociais e na mídia brasileira e mundial. (ASSOCIAÇÃO DOS MAGISTRADOS DO BRASIL, 2019, p. 8-9).
} 
maiores do ordenamento jurídico, fundamentos do Estado Democrático de Direito, trazendo consigo o conteúdo político-constitucional erigido pela sociedade contemporânea, servindo de instrumental valioso para a aplicabilidade e efetividade das normas constitucionais e infraconstitucionais.

Registre-se, por oportuno, que os dados obtidos pelas pesquisas nacionais estão em consonância com as percepções de organismos internacionais.

A título ilustrativo, apresentamos os indicadores obtidos pela Comissão Econômica para a América Latina e o Caribe $(\mathrm{CEPAL})^{11}$, enfatizando a visão da opinião pública brasileira acerca da corrupção, identificando que 65\% (sessenta e cinco por cento) dos brasileiros concordam que se as leis que existem fossem cumpridas e não existisse a impunidade, a corrupção diminuiria, bem como, 66\% (sessenta e seis por cento) dos entrevistados concordam que o controle da corrupção exige leis novas, com penas mais duras e maiores.

Dando prosseguimento às pesquisas internacionais, apresentamos as percepções obtidas pela Transparência Internacional $(2019)^{12}$, identificando que $56 \%$ (cinquenta e seis por cento) dos brasileiros entendem que a corrupção aumentou nos últimos 12 meses, 90\%(noventa por cento) afirmam que a corrupção no âmbito governamental é um grande problema, $75 \%$ (setenta e cinco por cento) acham que seu governo é administrado por interesses particulares, $82 \%$ (oitenta e dois por cento) dos entrevistados no país acreditam que os cidadãos podem fazer a diferença na luta contra a corrupção e para $57 \%$ (cinquenta e sete por cento) dos cidadãos no Brasil denunciar atos de corrupção pode levar a mudanças.

Acrescente-se, ainda, os dados do Índice de Percepção da Corrupção (IPC) 2019, outro relatório produzido pela Transparência Internacional (2020), que avaliou o desempenho de 180 países, no qual o Brasil ficou classificado em $106^{\circ}$ lugar, pior colocação da série histórica do índice ${ }^{13}$.

\footnotetext{
${ }^{11}$ Para maiores informações quanto a pesquisa, cf. Comissão Econômica para a América Latina e o Caribe (2011), que foi desenvolvida pelo Instituto de Pesquisa Econômica Aplicada (IPEA).

${ }^{12}$ O Relatório Barômetro Global da Corrupção, conduzido pela Transparência Internacional (2019, p. 11), foi produzido no Brasil durante os primeiros nove meses da atual gestão da Presidência da República. Enfatizou que "o quadro anticorrupção do Brasil sofreu uma série de golpes. O Presidente [...] não deu muita atenção às acusações de corrupção contra membros de seu gabinete [...] a confiança dos cidadãos na capacidade do governo impedir e pôr um fim na corrupção pode retroceder em breve.”.

${ }^{13}$ Conforme o relatório da Transparência Internacional (2020, p. 4-5), houve um aumento nas tentativas de interferência política nas indicações para cargos estratégicos no combate à corrupção, com "substituições polêmicas na Polícia Federal e Receita Federal e nomeação de um Procurador-Geral da República fora da lista tríplice".
} 
Demais disso, conforme a investigação realizada pelo Latinobarómetro em $2018^{14}$, a corrupção aparece como o problema mais importante do país para $16 \%$ dos entrevistados do Brasil, que ficou com o $3^{\circ}$ maior índice percentual dos países latino americanos, atrás apenas da Colômbia (20\%) e do Peru (19\%).

Segundo Moisés (2013, p. 64-65), “a preocupação com a situação da corrupção sugere que existe na sociedade brasileira uma demanda por maior eficiência dos mecanismos de accountability.".

Nessa linha, a identificação de como a sociedade percebe e reflete quanto ao fenômeno da corrupção guarda compatibilidade com as contribuições da Teoria EstruturalFuncionalista desenvolvida por Durkheim e Merton, cujos os postulados que são significativos para a compreensão da dinâmica da criminalidade e das estruturas sociais, pois conforme as lições de Veras (2010, p. 8) tal teoria consiste no ponto de partida das escolas macrossociológicas que baseiam seus estudos sobre a criminalidade a partir das próprias instituições da sociedade.

Segundo Merton (1968, p. 188) as escolhas dos meios para a consecução dos objetivos pelos indivíduos é pautada a partir de uma carga valorativa no campo da eticidade, representando padrões definitivamente prescritos ou preferenciais ou permissivos ou proscritos de comportamento, e consequentemente, muitos procedimentos que, do ponto de vista de alguns indivíduos específicos, seriam mais eficientes em garantir os valores desejados - o exercício da força, fraude, poder - são descartados na área institucional da definição da conduta permitida.

Destarte, a escolha de expedientes para a busca de objetivos culturais é limitado por normas institucionalizadas, num processo de convergência ou aceitação entre os meios institucionais e os fins culturais pretendidos, e desta forma, a violação desses valores axiológicos pautados em critérios ético-sociais consiste justamente numa não aceitação dos meios institucionais, que caracterizará a conduta desviante, já que os fins justificariam a adoção de quaisquer meios para a sua consecução.

Na mesma linha, Shecaira (2012, p. 611-612) afirma que “a corrupção passa a ser tolerada e pessoas corruptas são, tendencialmente, encaradas como espertas ao invés de serem caracterizadas como criminosas.".

Desse modo, à medida que se acentua a desigualdade no tratamento da persecução

${ }^{14}$ A Corporação Latinobarómetro, organização não-governamental com sede em Santiago, no Chile, investiga o desenvolvimento da democracia, da economia e da sociedade usando indicadores de opinião pública que medem atitudes, valores e comportamentos em 18 países latino-americanos, com exceção de Cuba. 
penal, diante da seletividade e impunidade de crimes de colarinho branco, incentiva-se um processo de depreciação da legitimidade da atuação das instituições públicas em crimes dessa natureza, e isso repercute nas perspectivas da sociedade quanto ao fenômeno da corrupção, banalizando os atos de corrupção como algo normal, e sendo transmitido esse senso comum para as gerações subsequentes e inibindo as mudanças de paradigmas éticos e comportamentais.

Importante registrar os ensinamentos de Veloso (2020, p.2), que ao tratar dos impactos da corrupção afirma que:

\begin{abstract}
A sensação de impunidade em relação aos corruptos é plenamente justificada pela demora nos julgamentos e no início do cumprimento da pena. Isto deixa a impressão de que vale a pena desviar dinheiro público no Brasil. [...] Enquanto isso, o governo alardeia que precisa cercear direitos sociais, previdenciários e cortar verbas para a saúde e educação porque há um rombo de R \$ 170 bilhões no orçamento público. Em outras palavras, a população vai suportar o ônus pela prática nefasta dos corruptos e dos corruptores. Desviam e se apropriam do dinheiro público e a sociedade paga a conta. É o dinheiro público saindo pelo ralo da corrupção.
\end{abstract}

Conforme Barroso (2021, p. 4, grifo do autor):

[...] um direito penal seletivo e absolutamente ineficiente em relação à criminalidade de colarinho branco criou um país de ricos delinquentes. O país da fraude em licitações, da corrupção ativa, da corrupção passiva, do peculato, da lavagem de dinheiro sujo. O direito penal deixou de cumprir o seu papel principal que é o de funcionar como prevenção geral: é o temor da punição que inibe os comportamentos criminosos. No atual estágio da condição humana, o bem nem sempre consegue se impor por si próprio. A ética, o ideal de vida boa precisa de um impulso externo também.

Segundo Nucci (2015, p. 3), "cuida-se, pois, de uma cultura a ser combatida, invertendo os valores e demonstrando que a retidão é melhor que a corrupção, inclusive para investimentos.".

Corroborando este entendimento, relativamente à percepção do combate à corrupção pela sociedade, válidas são as considerações de Colen (2010), ao afirmar que há uma tendência de melhor valoração e maior confiança nas instituições democráticas por aqueles que acreditam que a corrupção esteja sendo efetivamente combatida.

Necessário que a sociedade compreenda que os atos de corrupção, além de consistirem em crimes contra a Administração Pública, configuram atos atentatórios contra toda a sociedade, pois, conforme Furtado $(2018$, p. 33) “[...] se verifica que a primeira vítima da corrupção é o Estado contratante, o que, em última instância, importa em transferir o ônus da contratação superfaturada para toda a coletividade".

Nessa perspectiva, estimulará o despertar da população para a compreensão de que também é protagonista do enfrentamento à corrupção, como reflexo do exercício cívico, 
através de atitudes simples do dia a dia, repudiando os pequenos atos de corrupção, seja se valendo do exercício do controle sobre os atos da administração pública, como por exemplo as consultas aos portais da transparência e denúncias aos órgãos de ouvidoria e à rede de controle da gestão pública, e, especialmente, mediante o pleno e livre exercício do voto, expressão da democracia participativa.

Portanto, o Judiciário não pode ficar alheio a esta realidade, e deve estar alinhado a este novo paradigma constitucional e dos anseios da sociedade. Nessa linha, Barroso (2018, p. 33) sustenta a necessidade de mudança de paradigmas:

[...] o combate à criminalidade do colarinho branco, especialmente da corrupção,
tem exigido mudanças de atitude na sociedade e nas instituições; mudaças na
legislação; e mudanças na jurisprudência dos tribunais. [...] A sociedade
demonstrou de forma ativa a sua rejeição a práticas promíscuas entre o setor privado
e o Poder Público, historicamente presentes na vida nacional. E o Supremo Tribunal
Federal foi capaz de interpretar esse sentimento e, num ponto fora da curva - que
veio a mudar a curva - decretou a condenação de mais de duas dezenas de pessoas,
entre empresários, políticos e servidores públicos, por delitos como corrupção ativa
e passiva, peculato, lavagem de dinheiro, evasão de divisas e gestão fraudenta de
instituição financeira.

Diante desse panorama, reforça-se a necessidade da atuação transparente e efetiva das instituições do Sistema de Justiça na persecução a tais espécies de ilícitos, como fatores importantes para influenciar a mudança de paradigma dos cidadãos relativamente à atuação das instituições públicas, na medida em que a maior efetividade na aplicação da lei e na persecução penal de crimes de corrupção tendem a criar um ambiente mais propício para o aumento da confiança social.

\section{CONSIDERAÇÕES FINAIS}

A prática de crimes contra a Administração Pública e atos de corrupção consistem em graves violações a Direitos Humanos na medida em que comprometem o alcance dos objetivos institucionais para os quais o Estado foi concebido e inviabilizam a efetiva aplicação em políticas públicas que dariam efetividade aos direitos fundamentais, na medida em que são os recursos destinados às políticas públicas os mais afetados pelos desvios éticos na administração pública.

Por conseguinte, o enfrentamento à corrupção consiste num dos grandes desafios das instituições do Sistema de Justiça na contemporaneidade e justifica a adoção de estratégias institucionais de prevenção e repressão pelos órgãos que compõem o sistema de controle social formal do Estado, encarregados da persecução penal.

Demais disso, infere-se a necessidade de aprofundamento e expansão do debate 
acerca do combate à corrupção para todas as camadas sociais, como uma pauta de interesse nacional e para o fortalecimento do Estado Democrático de Direito, viabilizando um processo de conscientização para a mudança de paradigma da percepção dos impactos da corrupção e também para uma mudança do comportamento em geral, com ênfase nos efeitos maléficos da corrupção no âmbito econômico, político e social.

Nessa linha, é importante ser ressaltada a preocupação da ONU acerca da temática do enfrentamento à corrupção, reconhecendo a necessidade de cooperação internacional e da implementação de um enfoque amplo e multidisciplinar para prevenir e combater eficazmente a corrupção.

Destarte, são significativas as contribuições da ONU ao enfrentamento à corrupção, seja através da coordenação da cooperação internacional, elaboração de tratados internacionais sobre a temática, para adoção de procedimentos uniformes, e contemplando o combate à corrupção em suas metas estratégicas para o desenvolvimento sustentável, sinalizando uma orientação à comunidade internacional para um maior esforço para a implementação de políticas efetivas contra a corrupção, mediante a participação da sociedade e refletindo princípios do Estado de Direito tais como a integridade, a transparência e a accountability, entre outros.

Nesse cenário, a partir das pesquisas científicas apresentadas no presente estudo, evidenciou-se uma expectativa de boa parte da população de que a Administração Pública seja pautada em valores éticos, de integridade e em consonância com a probidade, repercutindo na percepção da sociedade quanto a atuação das Instituições do Sistema de Justiça Criminal e quanto ao paradigma da persecução penal.

Corroborando as argumentações já aduzidas, evidencia-se, portanto, que o enfrentamento à corrupção consiste em uma política pública constitucional prioritária de um Estado Democrático de Direito, eis que tem conexão com valores e princípios fundamentais da República, consagrados no próprio texto constitucional. Portanto, resta induvidoso que o interesse no aprimoramento e efetividade da persecução penal estatal com repercussão na chamada corrupção administrativa.

Destaque-se, ainda, as percepções da sociedade em geral com relação ao comando punitivo emanado dos órgãos de controle social formal, seja como destinatário indireto da orientação punitiva e suas consequências como contraestímulo para novas práticas delitivas, bem como, na qualidade de destinatário do serviço judiciário, servindo a divulgação da sentença como uma espécie de prestação de contas do Poder Judiciário, com um caráter 
simbólico, passível de revisão pelo público em geral.

Portanto, a atuação do Poder Judiciário impacta significativamente na percepção da sociedade quanto ao paradigma do enfrentamento à corrupção, como forma de conferir maior legitimidade e credibilidade ao exercício da prestação jurisdicional, compatibilizando-se com a preservação dos princípios constitucionais, refletindo e estruturando as novas tendências e anseios da sociedade, que passa a pugnar pelo compromisso com a eficiência, a transparência e integridade no trato da res pública, seja para a otimização dos gastos públicos, com a devida aplicação, seja através de mecanismos de prevenção, de enfrentamento e punição aos atos de corrupção.

Diante desse panorama, evidencia-se a necessidade de ações integradas de todos os níveis federativos e unidade de esforços e desígnios de todas as instituições públicas e privadas em torno da temática, integrando uma rede internacional de enfrentamento à corrupção, refletindo e estruturando novas tendências para a consolidação de cenário propício às mudanças de paradigmas, com a otimização de estratégias de prevenção e de combate aos atos de corrupção na contemporaneidade, em consonância com a dogmática jurídico-penal.

\section{REFERÊNCIAS}

\section{ASSOCIAÇÃO DOS MAGISTRADOS BRASILEIROS. Estudo da Imagem do} Judiciário Brasileiro. Disponível em: https://www.amb.com.br/wp-content/uploads/2020/04/ESTUDO_DA_IMAGEM_.pdf. Acesso em: 10 jun. 2020.

\section{BARROSO, Luís Roberto. A Judicialização da vida e o papel do Supremo Tribunal} Federal. Belo Horizonte: Fórum, 2018.

BARROSO, Luís Roberto. O momento institucional brasileiro e uma agenda para o futuro. Disponível em: https://luisrobertobarroso.com.br/wpcontent/uploads/2017/08/Oxford-Momento-institucional-brasileiro-e-uma-agenda-para-ofuturo.pdf. Acesso em: 25 fev. 2021.

BRASIL. Presidência da República. Decreto no 3.678, de 30 de novembro de 2000. Promulga a Convenção sobre o Combate da Corrupção de Funcionários Públicos Estrangeiros em Transações Comerciais Internacionais, concluída em Paris, em 17 de dezembro de 1997. Disponível em:

http://www.planalto.gov.br/ccivil_03/decreto/d3678.htm\#: :text=Promulga\%20a\%20Conve n\%C3\% A7\%C3\%A3o\%20sobre\%20o,17\%20de\%20dezembro\%20de\%201997. Acesso em 22 mar. 2021.

BRASIL. Presidência da República. Decreto no 4.410, de 7 de outubro de 2002. Promulga a Convenção Interamericana contra a Corrupção, de 29 de março de 1996, com reserva para o 
art. XI, parágrafo 1o, inciso "c". Disponível em:

http://www.planalto.gov.br/ccivil_03/decreto/2002/d4410.htm. Acesso em: 22 mar. 2021.

BRASIL. Presidência da República. Decreto no 5.015, de 12 de março de 2004. Promulga a Convenção das Nações Unidas contra o Crime Organizado Transnacional. Disponível em: http://www.planalto.gov.br/ccivil_03/_ato2004-2006/2004/decreto/d5015.htm. Acesso em: 22 mar. 2021.

BRASIL. Presidência da República. Decreto no 8.892, de 27 de outubro de 2016. Cria a Comissão Nacional para os Objetivos de Desenvolvimento Sustentável. Disponível em: http://www.planalto.gov.br/ccivil_03/_ato2015-

2018/2016/decreto/d8892.htm\#: :text=DECRETA\%3A,pela\%20Rep\%C3\%BAblica\%20Fed erativa\%20do\%20Brasil. Acesso em 22 mar. 2021.

COLEN, Célia Mara Ladeia. As covariantes da confiança política na América Latina.

Opinião Pública, Campinas, v. 16, n. 1, p. 1-27, jun. 2010. ISSN 0104-6276. DOI: https:// doi.org/10.1590/S0104-62762010000100001. Disponível em:

http://www.scielo.br/scielo.php?script=sci_arttext\&pid=S0104-

62762010000100001\&lng=en\&nrm=iso. Acesso em: 25 fev. 2021.

COMISSÃO ECONÔMICA PARA A AMÉRICA LATINA E O CARIBE (ONU). Corrupção e controles democráticos no Brasil. Brasília, DF: CEPAL. Escritório no Brasil, 2011. 40p.

CONSELHO NACIONAL DE JUSTIÇA (Brasil). Agenda 2030 no Poder Judiciário: comitê interinstitucional. Brasília, DF: CNJ, 2021. Disponível em: https://www.cnj.jus.br/agenda2030/. Acesso em: 22 mar. 2021.

CONSELHO NACIONAL DE JUSTIÇA (Brasil). Pacto pela Implementação dos Objetivos de Desenvolvimento Sustentável da Agenda 2030 no Poder Judiciário e Ministério Público. Brasília, DF: CNJ, 19 ago. 2019a. Disponível em: https://www.cnj.jus.br/wpcontent/uploads/2019/09/578d5640079e4b7cca5497137149fa7f.pdf. Acesso em 30 dez. 2020.

CONSELHO NACIONAL DE JUSTIÇA (Brasil). Portaria no 119, de 21 de agosto de 2019. Institui o Laboratório de Inovação, Inteligência e Objetivos de Desenvolvimento Sustentável (LIODS) e dá outras providências. Brasília, DF: CNJ, 21 ago. 2019b. Disponível em: https://atos.cnj.jus.br/atos/detalhar/2986. Acesso em: 30 dez. $2020 \mathrm{~d}$.

CONSELHO NACIONAL DE JUSTIÇA (Brasil). Resolução CNJ nº 325, de 29 de junho de 2020. Dispõe sobre a Estratégia Nacional do Poder Judiciário 2021-2026 e dá outras providências. Brasília, DF: CNJ, 29 jun. 2020. Disponível em:

https://atos.cnj.jus.br/atos/detalhar/3365. Acesso em: 30 dez. 2020.

CORPORAÇÃO LATINOBARÓMETRO. Informe Latinobarómetro 2018. Disponível em: http://www.latinobarometro.org/latdocs/INFORME_2018_LATINOBAROMETRO.pdf. Acesso em: 12 jun. 2020. 
FLORÊNCIO FILHO, Marco Aurélio Pinto; SILVA, Amanda Scalisse. A Repercussão da Governança Corporativa na Responsabilidade Penal da Pessoa Física e Jurídica. In: BECHARA, Fábio Ramazzini; FLORÊNCIO FILHO, Marco Aurélio Pinto (coord.). Compliance e Direito Penal Econômico. São Paulo: Almedina, 2019. p. 235-256.

FUNDAÇÃO GETÚliO VARGAS. Diretoria de Análise de Políticas Públicas. O dilema do brasileiro: entre a descrença no presente e a esperança no futuro. Rio de Janeiro: FGV, DAPP, 2017. ISBN 978-85-68823-46-0. Disponível em: http://dapp.fgv.br/o-dilemabrasileiroentre-descrenca-no-presente-e-esperanca-no-futuro/. Acesso em 26 abr. 2020.

FURTADO, Lucas Rocha. Brasil e Corrupção: análise de casos (inclusive da Operação Lava Jato). Belo Horizonte: Fórum, 2018.

GODINHO, Thiago José Zanini. Contribuições do Direito Internacional ao combate à corrupção. Revista da Faculdade de Direito da Universidade Federal de Minas Gerais, Belo Horizonte, n. 58, p. 347-386, jan./jun. 2011. ISSN 1984-1841. Disponível em: https://www.direito.ufmg.br/revista/index.php/revista/article/view/147/137. Acesso em: 30 out. 2020.

GUSTIN, Miracy Barbosa de Sousa; DIAS, Maria Thereza Fonseca. (Re)pensando a Pesquisa Jurídica: teoria e prática. 4. ed. Belo Horizonte: Del Rey Editora. 2015.

MERTON, Robert K. Social Theory and Social Structure: enlarged to include two new essays on theoretical sociology. New York: Macmillan, 1968.

MOISÉS, José Álvaro. Cidadania, confiança política e instituições democráticas. A desconfiança política e os seus impactos na qualidade da democracia. São Paulo: Editora da Universidade de São Paulo, 2013. Disponível em:

http://www.nupps.usp.br/downloads/relatorio2013/Anexo_65_Livro_EDUSP_2013_versao_e nviada.pdf. Acesso em: 14 jun. 2020.

ORGANIZAÇÃO DAS NAÇÕES UNIDAS (ONU). Assembleia Geral das Nações Unidas. Agenda 2030 para o desenvolvimento sustentável. Disponível em: https://brasil.un.org/ptbr/91863-agenda-2030-para-o-desenvolvimento-sustentavel. Acesso em 22 mar. 2021a.

ORGANIZAÇÃO DAS NAÇÕES UNIDAS (ONU). Assembleia Geral das Nações Unidas. Escritório das Nações Unidas sobre Drogas e Crime. Convenção das Nações Unidas contra a Corrupção. Disponível em: https://www.unodc.org/documents/lpobrazil//Topics_corruption/Publicacoes/2007_UNCAC_Port.pdf. Acesso em 22 mar. 2021b.

ORGANIZAÇÃO DAS NAÇÕES UNIDAS (ONU). Centro de Informação das Nações Unidas no Brasil (UNICRIO). Conferência em Abu Dhabi amplia esforços de combate à corrupção no mundo. Disponível em: https://unicrio.org.br/conferencia-em-abu-dhabiamplia-esforcos-de-combate-a-corrupcao-no-mundo/. Acesso em 22 mar. 2021c.

ORGANIZAÇÃO DAS NAÇÕES UNIDAS (ONU). Pacto Global da ONU. Disponível em: https://www.unglobalcompact.org/what-is-gc/mission/principles. Acesso em 22 mar. 2021d.

PINHEIRO, Igor Pereira; PINHEIRO, Tânia Mara Moreira Sales. Entenda o Sistema Brasileiro Anticorrupção. Leme, SP: JH Mizuno, 2020. 
SADEK, Maria Tereza. A crise do Judiciário vista pelos Juízes: resultados de uma pesquisa quantitativa. In: Uma introdução ao estudo da justiça. Rio de Janeiro: Centro Edelstein de Pesquisas Sociais, 2010. 118 p. ISBN: 978-85-7982-032-8.

SHECAIRA, Sérgio Salomão. Corrupção: uma análise criminológica. In: GRECO, Luis; MARTINS, Antonio (org.). Direito penal como crítica da pena: estudos em homenagem a Juarez Tavares por seu $70^{\circ}$ aniversário em 2 de setembro de 2012. Madrid: Marcial Pons, 2012.

SILVA, Priscila Nascimento. A contribuição do Direito Internacional para a Prevenção e Repressão da Corrupção. In: BECHARA, Fábio Ramazzini; FLORÊNCIO FILHO, Marco Aurélio Pinto (coord.). Compliance e Direito Penal Econômico. São Paulo: Almedina, 2019.

TORRES, Rafael Lima; BERTONCINI, Mateus Eduardo Siqueira Nunes. Combate à corrupção, crimes econômicos, teorias criminológicas correlatas e ética empresarial. In: SANTOS, Bartira Macedo Miranda; RIBEIRO, Luiz Gustavo Gonçalves; MELLO, Marília Montenegro Pessoa de (org.). Criminologias e política criminal. Florianópolis: CONPEDI, 2015. p. 176-198.

TRANSPARÊNCIA INTERNACIONAL. Barômetro global da corrupção: américa latina e caribe 2019. Opiniões e experiências dos cidadãos relacionadas à corrupção. 2019. ISBN: 978-3-96076-126-6. Disponível em:

https://comunidade.transparenciainternacional.org.br/asset/54:bgc---barometro-global dacorrupcao-2019?stream=1. Acesso em: 25 fev. 2021.

TRANSPARÊNCIA INTERNACIONAL. Índice de percepção da corrupção 2019.

Disponível em: https://transparenciainternacional.org.br/ipc/. Acesso em: 10 maio 2020.

TRANSPARÊNCIA INTERNACIONAL. Novas Medidas contra a Corrupção. Rio de Janeiro: FGV Editora, 2018.

VELOSO, Roberto Carvalho. A corrupção e a impunidade. Disponível em: https://www.huffpostbrasil.com/roberto-carvalho-veloso/a-corrupcao-e-aimpunidade_a_23038084/. Acesso em: 20 jun. 2020.

VERAS, Ryanna Pala. Nova criminologia e os crimes do colarinho branco. São Paulo: Editora WMF Martins Fontes, 2010. 